\title{
DETERMINAN PENDIDIKAN DAN PENGETAHUAN TERHADAP PEMBERIAN IMUNISASI PADA BAYI DI WILAYAH KERJA PUSKESMAS KAMPEONAHO KOTA BAU-BAU
}

\section{DETERMINANTS OF EDUCATION AND KNOWLEDGE OF IMMUNIZATION FOR INFANTS IN THE WORKING AREA OF THE KAMPEONAHO HEALTH CENTER, BAU-BAU CITY}

\author{
Ni'ma Meilani ${ }^{1}$, Agus Darmawan ${ }^{1}$, Wahyuddin ${ }^{1}$, Dahmar $^{1}$, \\ Megawati $^{2}$, Adius Kusnan ${ }^{3}$ \\ ${ }^{1}$ Dosen Kesehatan Masyarakat, Universitas Dayanu Ikhsanuddin \\ ${ }^{2}$ Mahasiswa Kesehatan Masyarakat, Universitas Dayanu Ikhsanuddin \\ ${ }^{3}$ Departemen Keperawatan, Fakultas Kedokteran, Universitas Halu Oleo \\ Korespondensi: adiuskusnan.fkuho@gmail.com
}

\begin{abstract}
The immunization coverage in the work area of the Kampeonaho Community Health Center in 2018 from January to December was 62.1\%. There are still many mothers who do not bring their children to be immunized. The purpose of this study is to find out the factors that influence the delivery of immunizations to infants in the working area of Kampeonaho City Bau-bau Health Center. This type of research is quantitative with a cross-sectional approach. The total population of 83 people. The sample in this study was taken using a total sampling technique. Data collection through primary data and secondary data. Data processing and analysis using the SPSS program with univariate and bivariate (chi-square) data analysis. The results showed that there was education with a significance value of $0.041<0.05$, knowledge with a significance value of 0.050 $<0.05$ on immunization for infants in the working area of Kampeonaho City, Bau-bau City. This study concludes that there is a relationship between education status and knowledge of immunization for infants in the working area of the Kampeonaho Health Center, Bau-bau city..
\end{abstract}

Keywords: Education, Knowledge, Provision of Immunization

\begin{abstract}
ABSTRAK
Cakupan imunisasi di wilayah kerja Puskesmas Kampeonaho pada tahun 2018 dari bulan Januari sampai bulan Desember sebanyak 62,1\%. Masih banyak para ibu yang tidak membawa anaknya untuk di imunisasi.Tujuan penelitian ini adalah untuk mengetahui faktor-faktor yang memengaruhi pemberian imunisasi pada bayi di wilayah kerja Puskesmas Kampeonaho Kota Bau-bau. Jenis penelitian yang digunakan adalah kuantitatif dengan pendekatan cross sectional. Jumlah populasi sebanyak 83 orang. Sampel dalam penelitian ini diambil dengan menggunakan teknik total sampling. Pengumpulan data melalui data primer dan data sekunder. Pengolahan dan analisis data dengan menggunakan program SPSS dengan analisis data univariat dan bivariat (chi square). Hasil penelitian menunjukkan bahwa ada antara pendidikan dengan nilai
\end{abstract}


signifikasinya $0,041<0,05$, pengetahuan dengan nilai signifikasinya $0,050<0,05$ terhadap pemberian imunisasi pada bayi di wilayah kerja Puskesmas Kampeonaho Kota Bau-bau. Kesimpulan dari penelitian ini yaitu ada hubungan status pendidikan dan pengetahuan terhadap pemberian imunisasi pada bayi di wilayah kerja Puskesmas Kampeonaho Kota Bau-bau.

\section{Kata Kunci: Pendidikan, Pengetahuan, Pemberian Imunisasi}

\section{PENDAHULUAN}

Salah satu program dalam pembangunan

dibidang kesehatan adalah imunisasi, dan sudah terbukti ampuh secara ilmiah dari berbagai hasil riset, dapat menekan angka kematian bayi akibat penyakit yang dapat dicegah dengan imunisasi (PD3I). Daya tahan tubuh anak terhadap penyakit setelah mendapatkan vaksin imunisasi lebih optimal, sehingga meskipun sakit tetapi tidak akan parah sedangkan yang tidak mendapatkan imunisasi mempunyai resiko tinggi terjangkit penyakit (Kepmenkes Republik Indonesia, 2004).

Pelaksanaan imunisasi di Puskesmas diintegrasikan kedalam program lain dengan konsep menekankan peran serta masyarakat pada setiap kegiatan yang secara teknis menunjuk anggota masyarakat yang berperan sebagai kader yang disebut kader posyandu, sehingga konsep ini lebih dititiberatkan untuk masyarakat dimana petugas kesehatan hanya sebagai pendamping untuk memberikan dukungan secara tekhnis (Muninjaya, 2010).

Untuk dapat meningkatkan efektifitas program imunisasi terhadap penyakit maka pemerintah menargetkan cakupan sebesar $\geq 80 \%$ selain harus memperhatikan faktor lain seperti cold chain. Salah satu program perioritas dari sebelas program yang telah ditetapkan dalam program pembangunan nasional adalah imunisasi bayi lengkap (Kamaluddin, 2012).

Secara umum penyelenggaraan pelayanan kesehatan perlu didukung dengan upaya perencanaan yang baik, agar tujuan yang diharapkan bisa tercapai. Selain itu keberhasilan penyelenggaraan kesehatan dapat dievaluasi bila input, proses atau output yang diharapkan dapat ditunjang oleh kemampuan dan potensi yang ada. Perencanaan disusun didasarkan atas prinsip-prinsip yang baik. Karena pentingnya peranan perencanaan tersebut, maka wajib bagi semua pihak yang bergerak dalam bidang kesehatan 
untuk memiliki pengetahuan dan imunisasi, budaya dan keyakinan keterampilan yang cukup tentang perencanaan (Azwar, 2010).

Gambaran pencapaian target cakupan desa UCI (Universal Child) masih sangat bervariasi dan menunjukkan grafis yang tidak stabil, pada tahun 2013 mencapai 60,59\%, $85,37 \%$ di tahun $2014,82,38 \%$ di tahun 2015, 82,87\% di tahun 2016 menjadi $85,92 \%$ pada tahun 2017. Hasil ini dapat dikatakan cukup baik, namun masih perlu terus ditingkatkan agar dapat mencakup seluruh desa/kelurahan diSulawesi Tenggara. Berdasarkan target Renstra Kementerian Kesehatan tahun 2017, persentase desa UCI Sulawesi Tenggara belum mencapai target dimaksud karena baru mencapai 85,92\%, lebih tinggi dari capaian tahun 2016 sebesar $82,87 \%$. Meskipun secara ratarata provinsi belum mencapai target, tapi setidaknya ada 2 kabupaten yang telah mencapai target yaitu Kabupaten Buton $(95,7 \%)$ dan Kota Kendari (98.46\%) dari target restra sebesar 95\%. Masih banyaknya faktor penghambat tercapainya cakupan imunisasi menjadi penyebab capaian cakupan imunisasi setiap tahunnya. Beberapa faktor penghambat tersebut adalah aspek pengetahuan masyarakat tentang faedah terhadap vaksin yang dapat menimbulkan kondisi fatal pada bayi, tingkat pendidikan masyarakat terutama masyarakat di daerah pedesaan yang masih minim, dan tidak kalah penting adalah aspek geografis wilayah dimana petugas kesehatan sulit menjangkau tempat tinggal bayi seperti yang terjadi di beberapa daerah pedalaman dan juga kondisi masyarakat yang sering kali hidup berpindah-pindah sehingga mengacaukan sistem pelaporan program imunisasi (Dinkes Provinsi Sulawesi Tenggara, 2018).

Berdasarkan penelitian yang dilakukan oleh Wahyuni (2015) dengan judul faktor-faktor yang berhubungan dengan capaian cakupan universal child (uci) di wilayah kerja Puskesmas Betoambari kota Bau-bau. Hasil penelitian menunjukan bahwa terdapat hubungan pendidikan dengan nilai $\mathrm{p}=0,008$, pekerjaan dengan nilai $\mathrm{p}=0,023$, pengetahuan dengan nilai $\mathrm{p}=0,021$, dukungan keluarga dengan nilai $\mathrm{p}=0,015$ dengan capaian umunisasi di Puskesmas Betoambari (Wahyuni, 2015).

Profil kesehatan di Dinas Kesehatan Kota Baubau, bahwa pada tahun 2015 capaian imunisasi lengkap 
mencapai 65,5 \%, tahun 2016 capaian imunisasi lengkap dari umur 0-11 bulan turun menjadi $60,1 \%$, sedangkan pada tahun 2017 capaian imunisasi lengkap sebesar 68\%. Hal ini menggambarkan bahwa masih ada masalah yang belum sepenuhnya dapat terselesaikan, khususnya terkait dengan pelaksanaan program di Puskesmas tersebut (Dinkes Kota Bau-bau, 2018)

Wilayah Kerja Puskesmas Kampeonaho terdiri dari 3 wilayah kerja yaitu kelurahan Kampeonaho, kelurahan Tampuna dan kelurahan Palabusa. Pada tahun 2016 jumlah ibu yang memiliki bayi di wilayah kerja Puskesmas Kampeonaho yaitu sebanyak 368 orang yang terdiri dari kelurahan Kampeonaho yaitu sebanyak 176 orang dimana ibu yang rutin membawa bayinya setiap bulannya untuk di imunisasi yaitu sebanyak 111 orang jika dikumulasikan cakupan imunisasi di Kelurahan Kampeonaho hanya sekitar 63\%. Di Kelurahan Tampuna jumlah ibu yang memiliki bayi sebanyak 192 orang dimana ibu yang rutin membawa bayinya setiap bulannya untuk di imunisasi yaitu sebanyak 127 orang jika dikumulasikan cakupan imunisasi di kelurahan tampuna hanya sekitar $66 \%$. Dari data tersebut dapat disimpulkan bahwa cakupan imunisasi di wilayah kerja Puskesmas Kampeonaho pada tahun 2016 yaitu sebanyak $66,3 \%$ dimana belum mencapai target Puskesmas yaitu sebanyak $84 \%$

Pada tahun 2017 jumlah ibu yang memiliki bayi di wilayah kerja Puskesmas Kampeonaho yaitu sebanyak 395 orang yang terdiri dari kelurahan Kampeonaho yaitu sebanyak 188 orang dimana ibu yang rutin membawa bayinya setiap bulannya untuk di imunisasi yaitu sebanyak 121 orang jika dikumulasikan cakupan imunisasi di kelurahan Kampeonaho hanya sekitar 64,3\%. Di kelurahan Tampuna jumlah ibu yang memiliki bayi sebanyak 207 orang dimana ibu yang rutin membawa bayinya setiap bulannya untuk di imunisasi yaitu sebanyak 142 orang jika dikumulasikan cakupan imunisasi di kelurahan Tampuna hanya sekitar $68,5 \%$.

Dari data di atas dapat disimpulkan bahwa cakupan imunisasi di wilayah kerja Puskesmas Kampeonaho pada tahun 2017 yaitu sebanyak 68,2\% dimana belum mencapai target Puskesmas yaitu sebanyak $84 \%$ akan tetapi data tersebut mengalami peningkatan sebanyak 1,9\%(Puksemas Kampeonaho, 2018)

Pada tahun 2018 dari bulan Januari sampai bulan Desember jumlah 
ibu yang memiliki bayi di wilayah kerja Puskesmas Kampeonaho yaitu sebanyak 389 orang yang terdiri dari kelurahan Kampeonaho yaitu sebanyak 182 orang dimana ibu yang rutin membawa bayinya setiap bulannya untuk di imunisasi yaitu sebanyak 112 orang jika dikumulasikan cakupan imunisasi di kelurahan Kampeonaho hanya sekitar 61,5\%. Di kelurahan Tampuna jumlah ibu yang memiliki bayi sebanyak 207 orang dimana ibu yang rutin membawa bayinya setiap bulannya untuk di imunisasi yaitu sebanyak 129 orang jika dikumulasikan cakupan imunisasi di kelurahan Tampuna hanya sekitar $62,3 \%$.

Dari data di atas dapat disimpulkan bahwa cakupan imunisasi di wilayah kerja Puskesmas Kampeonaho pada tahun 2018 dari bulan Januari sampai bulan Desember yaitu sebanyak 62,1\% Menurut penanggung jawab imunisasi di Puskesmas data tersebut sudah cukup baik, pihak puskesmas akan terus melakukan sosialisasi kepada para ibu untuk membawa bayinya di imunisasi agar target cakupan imunisasi pada tahun 2018 dapat tercapai yaitu sebanyak 84\% (Puskesmas Kampeonaho, 2019)

Penelitian ini bertujuan untuk mengetahui hubungan status pendidikan dan pengetahuan terhadap pemberian imunisasi pada bayi di wilayah kerja Puskesmas Kampeonaho Kota Bau-bau Tahun 2018.

\section{METODE}

Jenis penelitian yang digunakan adalah kuantitatif dengan rancangancross sectional study, yaitu desain penelitian yang tidak memiliki dimensi waktu, artinya pengukuran terhadap seluruh variabelyang akan diteliti hanya dilakukan satu kali, pada waktu yang sama atau suatu periode (Sastroasmoro, 2014). Variabel bebas dalam penelitian ini adalah pendidikan, pengetahuan, pekerjaan, dan dukungan suami. Sedangkan variabel terikat adalah pemberian imunisasi.

Populasi dalam penelitian ini yaitu seluruh ibu yang memiliki bayi berumur 9-12 bulan di wilayah kerja Puskesmas Kampeonaho Kota Baubau tahun 2018 yang berjumlah sebanyak 83 . Pengambilan sampel dilakukan dengan teknik total sampling sehingga sampel penelitian ini seanyak 83 bayi. Analisis dalam penelitian ini menggunakan analisis univariate dan analisis bivariate menggunakan uji chi square pada tingkat kemaknaan $95 \%$. 


\section{HASIL DAN PEMBAHASAN}

\section{Analisis Univariat}

Pada analisis univariat ini, diperoleh karakteristik dan frekuensi variabel penelitian yang dapat dilihat pada tabel berikut:

Tabel 1. Distribusi Responden Berdasarkan Karakteristik Responden

\begin{tabular}{lcc}
\hline \multicolumn{1}{c}{ Karakteristik } & Jumlah (n) & Persentase (\%) \\
\hline $18-26$ & 34 & 41.0 \\
\hline $27-35$ & 36 & 43.4 \\
\hline $36-42$ & 13 & 15.7 \\
\hline \multicolumn{1}{c}{ Tingkat Pendidikan } & 4 & 4.8 \\
\hline Tidak Sekolah & 42 & 26.5 \\
\hline Tamat SD & 12 & 14.5 \\
\hline Tamat SMP & 29 & 34.9 \\
\hline Tamat SMA & 7 & 8.4 \\
\hline Diploma & 9 & 10.8 \\
\hline Perguruan Tinggi & & \\
\hline Jenis kelamin & 44 & 53.0 \\
\hline Laki-laki & & 47.0 \\
\hline Perempuan & & \\
\hline
\end{tabular}

Sumber: Data Primer, 2019

Berdasarkan tabel 11 jumlah responden terbanyak adalah menunjukkan bahwa distribusi responden yang lulus SMA sebanyak 29 responden berdasarkan umur jumlah orang (34.9\%) sedangkan jumlah responden terbanyak adalah responden terendah adalah responden yang tidak yang berada pada kelompok umur 27sekolah sebanyak 4 orang $(4.8 \%)$. Jenis 35tahun yaitu sebanyak 36 orang (43.4\%) sedangkan jumlah terendah adalah responden yang berada pada kelompok umur 36-42 tahun yaitu kelamin dengan jumlah terbanyak adalah responden laki-laki sebanyak 44 orang $(53 \%)$ sedangkan perempuan sebanyak 39 orang (47\%). sebanyak 13 orang (15.7\%). Pendidikan 
Tabel 2.Distribusi Responden Berdasarkan Variabel Penelitian

\begin{tabular}{ccc}
\hline Variabel Penelitian & Jumlah (n) & Persentase (\%) \\
\hline Status Pendidikan & & 41,8 \\
\hline Rendah & 40 & 48,2 \\
\hline Tinggi & 43 & 25.3 \\
\hline Pekerjaan & 21 & 74.7 \\
\hline Tidak Bekerja & 62 & 36,1 \\
\hline Bekerja & & 63,9 \\
\hline Pengetahuan & 30 & \\
\hline Kurang & 53 & 37.3 \\
\hline Baik & 31 & 62.7 \\
\hline Pemberian Imunisasi & 52 & \\
\hline Tidak Lengkap & & \\
\hline Lengkap & & \\
\hline
\end{tabular}

Sumber: Data Primer, 2019

Berdasarkan tabel 2 dapat diketahui bahwa dari 83 responden yang memiliki pendidikan rendah sebanyak 40 orang $(41,8 \%)$ sedangkan yang memiliki pendidikan tinggi yaitu sebanyak 43 orang $(48,2 \%)$. Responden yang memiliki pekerjaan tidak bekerja sebanyak 21 orang (25.3\%) sedangkan yang bekerja yaitu sebanyak 62 orang
(74.7\%). Responden yang memiliki pengetahuan kurang sebanyak 30 orang $(36,1 \%)$ sedangkan yang memiliki pengetahuan baik yaitu sebanyak 53 orang $(63,9 \%)$. Pemberian imunisasi tidak lengkap sebanyak 31 orang $(37.3 \%)$ sedangkan yang lengkap yaitu sebanyak 52 orang $(62.1 \%)$.

Tabel 3. Analisis Hubungan Antar Variabel Penelitian

\begin{tabular}{|c|c|c|c|}
\hline \multirow[t]{2}{*}{ Variabel Penelitian } & \multicolumn{2}{|c|}{ Pemberian Imunisasi } & \multirow[t]{2}{*}{ p value } \\
\hline & Tidak lengkap & Lengkap & \\
\hline \multicolumn{4}{|l|}{ Status Pendidikan } \\
\hline Rendah & 27 & 13 & 0,041 \\
\hline Tinggi & 18 & 25 & \\
\hline \multicolumn{4}{|l|}{ Pengetahuan } \\
\hline Kurang & 17 & 13 & 0,050 \\
\hline Baik & 24 & 29 & \\
\hline
\end{tabular}


Pada tabel 3 terlihat bahwa dari 40 responden yang memiliki status pendidikan rendah, lebih banyak memiliki pemberian imunisasi tidak lengkap sebanyak 27 responden, dan pada status pendidikan tinggi, lebih banyak ibu yang memberikan imunisasi pada bayinya sebanyak 25 responden. Uji chisquare menunjukkan bahwa nilai $\mathrm{p}$ value $0,041<0,05$ yang artinya bahwa ada hubungan status pendidikan dengan pemberian imunisasi pada balita.

Pada variabel pengetahuan kategori kurang, lebih banyak responden yang memiliki bayi imunisasi tidak lengkap sebanyak 17 responden dan pada ibu berpengetahuan baik, lebih banyak memiliki bayi imunisasi lengkap. Uji chisquare menunjukkan bahwa nilai $\mathrm{p}$ value $0,050<0,05$ yang artinya bahwa ada hubungan pengetahuan dengan pemberian imunisasi pada balita.

\section{Hubungan pendidikan terhadap}

\section{pemberian imunisasi pada bayi}

Berdasarkan hasil uji statistik bahwa antara pendidikan ibu dengan pemberian imunisasi pada balita berhubungan dengan nilai $\mathrm{p}$ value $=$ 0,041 yang artinya nilai signifikan pendidikan ibu lebih besar dari nilai probabilitas atau 0,041<0,05.

Pendidikan sangat berpengaruh dengan pemberian imunisasi pada balita karena semakin tinggi pendidikan ibu semakin bagus pengetahuannya, berdasarkan data hasil penelitian pendidikan rendah (tidak sekolahSMP)sebanyak 38 orang $(45,8 \%)$ sedangkan yang memiliki pendidikan tinggi (SMA-Perguruan Tinggi) sebanyak 58 orang $(54,2 \%)$. Berdasarkan data pendidikan ibu kebanyakan sebatas SMA yaitu sebanyak 29 orang (34.9\%) dan tamatan SD sebanyak 22 orang (26.5\%). Kecenderungan pendidikan akan memengaruhi kunjungan ibu ke posyandu untuk mengimunisasi anaknya, kurangnya pengetahuan ibu yang menganggap imunisasi tidak terlalu penting karena mereka berpikir walaupun tidak diimunisasi anaknya akan baik-baik saja karena anaknya tidak ada yang sakit walaupun tidak diimunisasi. Pendidikan seseorang berbeda-beda juga akan memengaruhi seseorang dalam pengambilan keputusan, pada ibu yang berpendidikan tinggi lebih mudah menerima suatu ide baru dibandingkan ibu yang berpendidikan rendah sehingga 
informasi lebih mudah dapat diterima dan dilaksanakan.

Sejalan dengan penelitian yang dilakukan Paridawati, dkk (2015) di Puskesmas Bajeng yang mendapatkan bahwa ada hubungan antara tingkat pendidikan ibu dengan tindakan pemberian imunisasi dasar. Pendidikan menjadi hal yang sangat penting dalam memengaruhi pengetahuan. Individu yang mempunyai tingkat pendidikan tinggi cenderung lebih mudah menerima informasi begitu juga dengan masalah informasi tentang imunisasi yang diberikan oleh petugas kesehatan, sebaliknya ibu yang tingkat pendidikannya rendah akan mendapat kesulitan untuk menerima informasi yang ada sehingga mereka kurang memahami tentang kelengkapan imunisasi (Paridawati et al., 2015).

Tingkat pendidikan yang diperoleh seseorang dari bangku sekolah formal dapat memengaruhi pengetahuan seseorang. Pendidikan kesehatan dapat membantu para ibu atau kelompok masyarakat disamping dapat meningkatkan pengetahuan juga untuk meningkatkan perilakunya untuk mencapai derajat kesehatan yang optimal. Tingkat pendidikan dan pengetahuan ibu sangat mempengaruhi terlaksananya kegiatan pelaksanaan imunisasi anak/bayi, baik itu pendidikan formal maupun non formal (Rahmawati AI, 2014).

\section{Hubungan pengetahuan terhadap} pemberian imunisasi pada bayi

\begin{tabular}{rrr}
\multicolumn{2}{c}{ Berdasarkan uji statistik } \\
menunjukkan bahwa & antara
\end{tabular}
pengetahuan ibu dengan pemberian imunisasi pada balita mempunyai nilai signifikan 0,050 yang artinya nilai signifikan pengetahuan ibu lebih kecil dari nilai probabilitas atau $0,050 \leq 0,05$ yang berarti terdapat korelasi yang signifikan antara pengetahuan dengan pemberian imunisasi pada bayi di Wilayah Kerja Puskesmas Kampeonaho Kota Bau-bau.

Berdasarkan hasil dari penelitian pengetahuan kurang sebanyak 30 orang (36.1\%) ini dikarenakan pendidikan ibu ada yang tidak sekolah dan kurangnya informasi yang diperoleh tentang pentingnya pemberian imunisasi pada bayi sehingga tidak membawa anaknya untuk diimunisasi sedangkan yang memiliki pengetahuan baik yaitu sebanyak 53 orang (63.9\%) dikarenakan pendidikan ibu yang tinggi dan memperoleh imunisasi melalui informasi penyuluhan tenaga kesehatan 
atau dari kader posyandu sehingga membawa anaknya untuk di imunisasi.

Pada ibu yang memiliki pengetahuan baik tentu ini akan sedikit membantu menciptakan perilaku yang positif sesuai yang diinginkan oleh petugas kesehatan yang secara tidak langsung akan meningkatkan nilai cakupan imunisasi, akan tetapi dilain pihak ibu yang memiliki pengetahuan kurang, baik secara langsung ataupun tidak langsung akan menghambat pencapaian target capaian atau cakupan imunisasi.

Berbicara tentang faktor penentu pengetahuan baik, dari responden dalam riset ini, tentu sudah banyak teori tentang hal ini, beberapa faktor tersebut sudah disebutkan di atas mulai dari tingkat pendidikan rendah dan tinggi yang bersinergi dengan pengetahuan baik dan kurang, begitupula peran kadar kesehatan atau petugas dalam upaya memahamkan masyarakat terutama bagi ibu bayi tentang faedah pemberian imunisasi bayi dan keluarga.

Berdasarkan penelitian yang dilakukan Prihanti, dkk bahwa variabel pengetahuan memiliki risiko 0,22 kali $(\mathrm{OR}=0,224)$ terhadap kelengkapan imunisasi dengan nilai CI antara 0,0540,928 CI $<1$ (Prihanti et al., 2016).
Artinya seorang ibu memiliki pengetahuan yang baik maka kemungkinan untuk melakukan imunisasi lengkap akan ditekan 0,22 kali dibandingkan dengan ibu yang pengetahuannya kurang.

Pengetahuan dapat diartikan sebagai kumpulan informasi yang dapat dipahami dan diperoleh dari proses belajar selama hidup dan dapat dipergunakan sewaktu-waktu sebagai alat untuk penyesuaian diri. Pengetahuan merupakan pengenalan terhadap kenyataan, kebenaran, prinsip dan kaidah suatu objek dan merupakan hasil stimulasi untuk terjadinya perubahan perilaku. Pengetahuan ibu tentang imunisasi akan memengaruhi keyakinan dan sikap ibu dalam kepatuhannya terhadap imunisasi. Kepatuhan terhadap perilaku pencegahan yang berkaitan dengan dunia medis merupakan fungsi dari keyakinan tentang kesehatan, ancaman yang dirasakan, persepsi kekebalan, pertimbangan mengenai hambatan atau kerugian misalnya biaya dan waktu keuntungan yaitu efektivitas dari anjuran medis tersebut (Prihanti et al., 2016).

Salah satu faktor perangsang seseorang berperilaku adalah 
pengetahuan. Oleh karena itu, jika pemerintah mempunyai program pengendalian penyakit dan menurunkan angka kesakitan dan kematian melalui program imunisasi, maka target utama adalah memperbaiki pengetahuan masyarakat untuk memperoleh perilaku yang positif (Rahmawati \& Umbul W, 2014).

Munculnya perilaku taat dalam melakukan imunisasi bagi seorang ibu adalah hasil atau output dari tingginya pengetahuan ibu terhadap imunisasi. Hal ini sejalan dengan pendapat L.Green bahwa pengetahuan merupakan salah satu faktor penentu terjadinya perubahan perilaku (Notoatmodjo, 2003).

Pada berbagai penelitian yang telah dilaksanakan termaksud pada penelitian ini sering dijumpai adanya beberapa responden yang memiliki pengetahuan kurang ada sebagian kecil yang status imunisasi anaknya lengkap. Hal ini dapat dijelaskan bahwa pengetahuan bukanlah satu satunya faktor yang memiliki peran tunggal dalam memengaruhi perubahan perilaku akan tetapi banyak faktor misalnya tingkat pendidikan, pekerjaan, stadisi, kepercayaan, aspek wilayah, politik dan lainnya (Wigunantiningsih, 2010).
Sehingga segala bentuk atribut atau karakter yang melekat pada individu yang diteliti dalam istilah riset disebut responden, inilah nanti yang memengaruhi variabel efek dalam hal ini perilaku ibu. Hal semacam ini sudah banyak dikemukakan oleh para pakar perilaku salah satunya adalah Lawrence Green dalam buku pendidikan dan perilaku kesehatan seperti dikutip oleh Notoatmodjo (Notoatmodjo, 2007).

\section{SIMPULAN}

Adapun Kesimpulan dalam penelitian ini yaitu status pendidikan dan pengetahuan berhubungan dengan pemberian imunisasi pada bayi di wilayah kerja Puskesmas Kampeonaho Kota Bau-bau Tahun 2019.

\section{DAFTAR PUSTAKA}
Azwar, A. (2010). Pengantar Adnministrasi Kesehatan. Binarupa Aksara.

Dinkes Kota Baubau. (2018). Profil Kesehatan Kota Baubau Tahun 2018.

Dinkes Provinsi Sulawesi Tenggara. (2018). Profil Kesehatan Provinsi Sulawesi Tenggara tahun 2017.

Kamaluddin. (2012). Pedoman Manajemen Puskesmas. Kementerian Kesehatan RI.

Kepmenkes Republik Indonesia, Pub. L. No. 1059/Menkes/SK/IX/2004 
(2004).

http://www.pdpersi.co.id/peraturan /kepmenkes/kmk10592004.pdf

Muninjaya. (2010). Manajemen Kesehatan. Penerbit Buku Kedokteran EGC.

Notoatmodjo, Soekidjo. (2007). Kesehatan Masyarakat Ilmu dan Seni (Rineka Cip).

Notoatmodjo, Soekijo. (2003). Pendidikan Dan Perilaku Kesehatan. Rineka Cipta.

Paridawati, W.A., R., \& Fajawati, I. (2015). Faktor Yang Berhubungan Dengan Tindakan Ibu Dalam Pemberian Imunisasi Dasar Pada Bayi Di Wilayah Kerja Puskesmas Bajeng Kecamatan Bajeng Kabupaten Gowa. http://repository.unhas.ac.id/

Prihanti, Sekar, G., Puteri, R. M., \& Najib, A. M. (2016). Faktor Faktor Yang Mempengaruhi Status Kelengkapan Imunisasi Dasar Diwilayah Kerja Puskesmas X Kota Kediri. Fakultas Kedokteran Universitas Muhammadiyah Malang. Saintika Medika, 12(2). http://ejournal.umm.ac.id/index.ph p/sainmed/article/view/5276

Puksemas Kampeonaho. (2018). Profil Kesehatan Puskemas Kampeonaho.
Puskesmas Kampeonaho. (2019). Profil

Kesehatan

Puskesmas

Kampeonaho Tahun 2018.

Rahmawati, A. I., \& Umbul W, C. (2014). Faktor Yang Mempengaruhi Kelengkapan Imunisasi Dasar Di Kelurahan Krembangan Utara. Jurnal Berkala Epidemiologi, 2(1), 59-70. https://e-

journal.unair.ac.id/JBE/article/dow nload $/ 162 / 32+\& \mathrm{~cd}=1 \& \mathrm{hl}=$ en $\& \mathrm{ct}=\mathrm{c}$ $\operatorname{lnk} \& \mathrm{gl}=\mathrm{id}$

Wahyuni. (2015). Faktor-faktor Yang Berhubungan Dengan Capaian Cakupan Universal Child Di Wilayah Kerja Puskesmas Betoambari Kota Baubau. Jurnal Kesehatan Masyarakat Unidayan.

Wigunantiningsih, A. (2010). Pengaruh Tingkat Pengetahuan Ibu Terhadap Status Imunisasi Dasar Lengkap Pada Bayi Usia 0-11 Bulan Di Desa Suruhkalang Kecamatan Tasik Madu Kabupaten Karanganyar. Maternal, 2(April). https://ejurnal.stikesmhk.ac.id/inde x.php/maternal/article/download/3 $91 / 356+\& \mathrm{~cd}=1 \& \mathrm{hl}=\mathrm{en} \& \mathrm{ct}=\mathrm{clnk} \&$ $\mathrm{gl}=\mathrm{id}$ 